\section{RCGP Annual Conference}

The Scots don't often take part in standing ovations and, while I enjoyed her talk, when Clare Gerada received one following her Chair of Council's address on the opening plenary of the Annual Primary Care Conference in Liverpool, I didn't get up. It just seemed too reminiscent of the atmosphere of a political party conference, too contrived.

Yet I was gradually won over. It was a fantastic conference. One of its key themes was generalism, and the notion that, increasingly, patients present to the GP with multiple complex problems at once; physical, psychological, social, and even spiritual, and while these problems need to be teased out, each one of them cannot be solved, to use Linn Getz's expression, within its own isolated silo, but that the analyses of all the problems need to be drawn together in a formulation unique to each individual patient'. This is almost a definition of what general practice is, and the idea that GPs are uniquely placed to give this kind of care is incredibly empowering. No less a figure than Sir Michael Rawlins, Chairman of NICE, stated (I paraphrase) 'it's only a guideline; if it doesn't make any sense to you with respect to a particular patient, drop it'

I wonder if this kind of advice is a reflection of a changed political landscape in England in which we see the targetdriven culture of Labour vanishing, to be replaced by the more laissez faire attitude of a Conservative-led coalition. There was very little discussion of appraisal, or QOF, or even SIGN, or NICE. Just when we thought the whole of medicine had been protocolised into a huge algorithm, the message from Liverpool is, 'Life isn't like that; it is infinitely more diverse. Everyone is unique.'

Andrew Lansley wants to hand a lot of power and freedom to GPs with the advice, again I paraphrase, if you think something doesn't work, fix it'. He wasn't given an easy ride. He wants to drive up quality by widening patient choice; and while conference was deeply suspicious of his agenda (there was only one supportive voice from the floor) it seemed to me that the College was not offering any alternative strategy to detect and eradicate bad practice. It's all very well to reiterate that the NHS is 'the envy of the world' but anybody who hasn't noticed that the NHS occasionally fails miserably must be living on another planet.

Still, the College heart is in the right place. I felt a rather perverse sense of pride when Detective Chief Superintendent John Carnochan, from the Scottish Violence Reduction Unit, talked about a deprived ward in Glasgow where I spent my first 3 years of life. That the College is deeply committed to giving the best care to the most disadvantaged is abundantly clear. John Carnochan's talk was another facet of Harry Burns' theme from the College conference in Glasgow 2 years ago, emphasising the importance of care and nurture in the earliest years of life. Richard Horton, editor of the Lancet, put some of these ideas into a global perspective in a very inspirational way.

I don't know that you come away from conferences like these resolved, let's say, to use dabigatran instead of warfarin in atrial fibrillation, but the nature of your practice is changed at a more fundamental level and, when Clare Gerada closed the conference with an exhortation to forgather in Glasgow next year, I was more than happy to stand up and applaud.

\section{Hamish Maclaren,}

GP, Aberfoyle and Buchlyvie Medical Practice, Main Street, Stirling, FK8 3UX. E-mail: hamish.maclarenavirgin.net

DOI: 10.3399/bjgp11X612954

\section{GP continuing professional development - done and dusted?}

The RCGP Conference, recently held in Liverpool, displayed an impressive 236 poster presentations divided into four categories. There were 35 posters in the education category. About $50 \%$ of the posters here were related to GP specialty training. Only two posters were on GP continuing professional development (CPD). The research section had 65 poster presentations, but only one on GP CPD.

Why is there such paucity in debate, analysis, and research into GP CPD? Are all pedagogical underpinnings of adult lifelong learning so firmly established as to make exploration in this area a fruitless venture? Have all avenues of critical enquiry into instructional strategies, learning quality, approach, methods, and evaluation been completely exhausted?

Current practice highlights the mechanics of the learning process. A learner will be considered fairly accomplished if they can independently decide on needs, goals, objectives, strategies, and reflection/evaluation of their learning. Even though this skill is laudable, in how many cases would a sequential mechanical process like this lead to higher critical thinking?

Critical thinking is vital because it facilitates a learner to think beyond that normal accepted knowledge framework, views, and biases. ' One could argue a GP who is performing poorly and lacks insight could still be a highly accomplished mechanical learner but would not stray beyond what he considers as 'right'. However, critical thinking skills do not come naturally and need to be taught, facilitated, and nurtured.

Current seismic changes going through the NHS necessitates a critical review of existing CPD practices. There is much to be said about Brookfield's penetrating insight into 'hegemonic' assumptions that seemed congenial but that actually work against our own best interests'.

Gen Wong,

Associate Clinical Director and GP Tutor, Salford/Northwest Deanery, Pendleton Way, Salford, M6 5FW.

E-mail: gwonglanhs.net

\section{REFERENCES}

1. Facione PA. Critical thinking: a statement of expert consensus for purposes of educational assessment and instruction. Millbrae, CA: The California Academic Press, 1990.

2. Brookfield SD. Becoming a critically reflective teacher. San Francisco, CA: Jossey-Bass, 1995.

DOI: 10.3399/bjgp11X612963 